\title{
Individual, local and subspecific variation in female Hermann's tortoise (Testudo hermanni) reproductive characters
}

\author{
S. Longepierre ${ }^{1,2}$, C. Grenot ${ }^{1} \&$ A. Hailey ${ }^{3,4}$ \\ 'Ecole Normale Supérieure, Laboratoire d'Ecologie, CNRS-UMR 7625, 46 rue d'Ulm, F-75005 Paris, \\ France; ${ }^{2}$ Present address: Laboratoire Environnement Marin Littoral, Gestion de la Biodiversité, E.A. Uni- \\ versité de Nice Sophia-Antipolis, Parc Valrose, 06108 Nice-Cedex 2-France; ${ }^{3}$ Department of Zoology, Aris- \\ totelian University of Thessaloniki, Thessaloniki GR 540-06, Greece; ${ }^{4}$ Present address: School of Biological \\ Sciences, University of Bristol, Woodland Road, Bristol BS8 IUG, U.K.
}

Keywords: Egg production, clutch characters, conservation, tortoise, Testudo hermanni

\begin{abstract}
We studied reproductive characters of a population of the tortoise Testudo h. hermanni in the Plaine des Maures (Var), and compared these to another population in southern France and to $T$. $h$. boettgeri in Greece. Clutch characters, which are measures of total reproductive investment, showed no differences between subspecies or sites after body size correction by ANCOVA. Egg characters, which measure the division of this investment among offspring, did vary significantly among both subspecies and sites after correcting for body mass. The presence of such local variation should discourage relocation of the threatened T. h. hermanni even between populations of the same subspecies.
\end{abstract}

\section{Contents}

Introduction

Material and methods $\quad 222$

Results

Discussion

Variation among individuals $\quad 225$

Conclusion

225

Acknowledgements

226

References

226

\section{Introduction}

Information on egg production is an important link between the study of population dynamics and the conservation of threatened tortoise species. Much work already exists on species of Gopherus in the USA (Diemer and Moore, 1994; Hellgren et al., 2000; Wallis et al., 1999), but data for European tortoises remain piecemeal. Reproductive data for
Hermann's tortoise, for example, mostly concern the eastern form, Testudo hermanni boettgeri (Cruce and Raducan, 1976; Hailey and Loumbourdis, 1988, 1990) even though the western form, Testudo hermanni hermanni (Bour, 1986), in France and Italy is more threatened. The few existing studies of $T$. $h$. hermanni have in addition been oriented more to reproductive behaviour than to the ecophysiology of egg production (Cheylan, 1981; Swingland and Stubbs, 1985), as very low population densities make capture of gravid females difficult.

A model of optimum body size in Greece suggested that the dwarf $T$. $h$. hermanni that occur in southern Italy were smaller than could be explained just by low adult survival rates, and that these therefore differed from $T$. $h$. boettgeri in reproduction or growth (Willemsen and Hailey, 2001). One important question is whether such differences largely occur between the two subspecies, or at a more local level among populations. This study therefore had two aims. First, to define the reproductive characteristics of threatened T. h. hermanni in the Plaine des Maures (France), and the relationships between investment in the egg and clutch and female size and body condition. Second, to analyse data on reproduction of $T$. hermanni to show whether there is significant variation among populations and/or subspecies. One possibly confounding factor in this analysis, annual variation, is apparently not important in $T$. hermanni. There were no significant differences in clutch or egg characters between 1982 and 1983 in France, or 1985 and 1986 in Greece, even though 1985 was a drought year (Hailey and Loumbourdis, 1988). 


\section{Material and methods}

The study site Pardiguière was situated in the locality of Cannet des Maures, in the Plaine des Maures, department of Var, France. This area $\left(43^{\circ} 11^{\prime} \mathrm{N}\right.$, $6^{\circ} 27^{\prime} \mathrm{E}$ ) has a typical Mediterranean climate with mild winters and hot, dry summers. A stream (usually dry in parts) crossed the study site, forming a small valley flanked by arid eroded areas of Permian sandy soil, with high diversity of xerophytic vegetation (Lavagne et al., 1998) but little shelter for tortoises. Scrub and forest (Quercus pubescens and Pinus pinea) in surrounding areas alternated with grassland and low maquis mixed with Cistus formations (Loisel, 1971). These provided large grazing areas and shelter to tortoises. Between the dense vegetation and the eroded areas were strips of shrubby vegetation belonging to the Isoetion (Aubert and Loisel, 1971; Barbero, 1965) and the Mediterranean Oleolentisc associations (Lavagne et al., 1998). Comparative data from T. h. boettgeri were from three sites in northern Greece (Willemsen and Hailey, 1989, 1999). Alyki - low coastal heathland on sandy soil with scattered Crataegus bushes and low thickets of Rubus, Artemisia and Cistus. Litochoron - tall macquis of Quercus coccifera on the lower slopes of Mount Olympus (altitude 450 $\mathrm{m})$, with shorter garrigue of $Q$. coccifera and Cistus scrub around grassland and cultivated areas. Deskati - open oak woodland of $Q$. ilex on poor soil at an altitude of $650 \mathrm{~m}$.

We captured 23 wild female $T$. h. hermanni from April-June 2000. Each female was X-ray imaged (Hailey and Loumbourdis, 1988, 1990) using Polaroïd Cronex film in a cartridge $(397 \times 297 \mathrm{~mm}$; radiation $10 \mathrm{~mA} \mathrm{~s}^{-1}$ for $0.06 \mathrm{~s}$ ), measured, marked, weighed (Stubbs et al., 1984), and released at the capture point. The number of calcified eggs was recorded for each individual, and the length (L, $\mathrm{mm}$ ) and width $(\mathrm{w}, \mathrm{mm})$ of the image of each egg was measured from the film to a precision of $0.5 \mathrm{~mm}$. The image was slightly magnified because the egg (within the female's body) was raised above the film. Observations of $T$. h. boettgeri in which eggs were measured on X-ray films in similar cartridges and after laying showed that the true egg width was $96 \%(\mathrm{SD}=2.8)$ of the image (A. Hailey, unpublished data). In that case the distance from the X- ray source to the film (F) was $70 \mathrm{~cm}$, so that the distance of the object $(\mathrm{O})$ from the source was 67.2 $\mathrm{cm}$ (i.e., $\mathrm{O} / \mathrm{F}=0.96$ ). The centres of the eggs (in a horizontal plane with the width shown on the Xray) were thus on average $2.8 \mathrm{~cm}$ above the film. In France, $F=84 \mathrm{~cm}$ and measurements from $\mathrm{X}$ rays were corrected using the ratio $\mathrm{O} / \mathrm{F}=0.97$, equivalent to the centres of the eggs being $2.5 \mathrm{~cm}$ above the film, because the tortoises were slightly smaller than the $T$. $h$. boettgeri. All clutches were from different individuals.

We calculated egg volume $\left(\mathrm{EV}, \mathrm{cm}^{3}\right)$ according to the equation: $\mathrm{EV}=\left(\mathrm{p}^{*} \mathrm{~L} * \mathrm{w}^{2}\right) / 6000$ (Coleman, 1991). We calculated egg mass (EM, g) from the equation $\mathrm{EM}=0.435 * \mathrm{~L}+0.0203 * \mathrm{w}^{2}-14.7$ (Hailey and Loumbourdis, 1990). Mean size, shape $(\mathrm{L} / \mathrm{w})$, mass, and volume of calcified eggs was calculated for each female. The clutch characters, clutch size (CS), clutch mass (CM), and clutch volume $(\mathrm{CV})$ were examined in relation to straight carapace length (SCL), body mass (BM), and body condition index $(\mathrm{CI})$ of females. We calculated the $\mathrm{CI}$ as the residual from the length - mass relationship: $\mathrm{CI}=\left(\mathrm{Y}_{\mathrm{o}}-\mathrm{Y}\right) / \mathrm{Y}$, where $\mathrm{Y}_{\mathrm{o}}$ and $\mathrm{Y}$ are the observed and predicted body masses, respectively. Interrelationships between these parameters were analyzed using polynomial, exponential, and linear regressions (Sokal and Rohlf, 1994; Zar, 1984), and the model explaining most variation (in term of $R^{2}$ and probability) was used.

Variation of egg, clutch, and female characters among populations and subspecies of T. hermanni in southern Europe was investigated using analysis of variance (ANOVA) and analysis of covariance (ANCOVA). One-way ANOVA of subspecies compared $T . h$. hermanni in France with $T . h$. boettgeri in Greece. One-way ANOVA of site compared three sites in Greece with tortoises of different body size. The same analyses were performed with ANCOVA, using SCL as covariate, thus correcting for differences in body size.

\section{Results}

The smallest female with eggs had a SCL of 148 $\mathrm{mm}$, which was considered as the size at maturity in females; the largest female was $169 \mathrm{~mm}$. The 


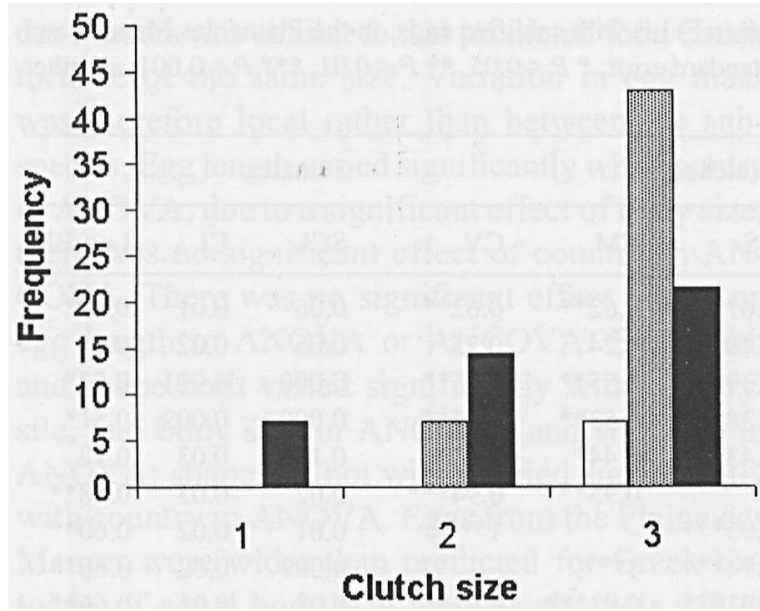

Fig. 1. The frequency distribution (\%) of clutch size for females of Testudo hermanni hermanni in southern France according to period (April $=$ white, May $=$ grey, June $=$ black).

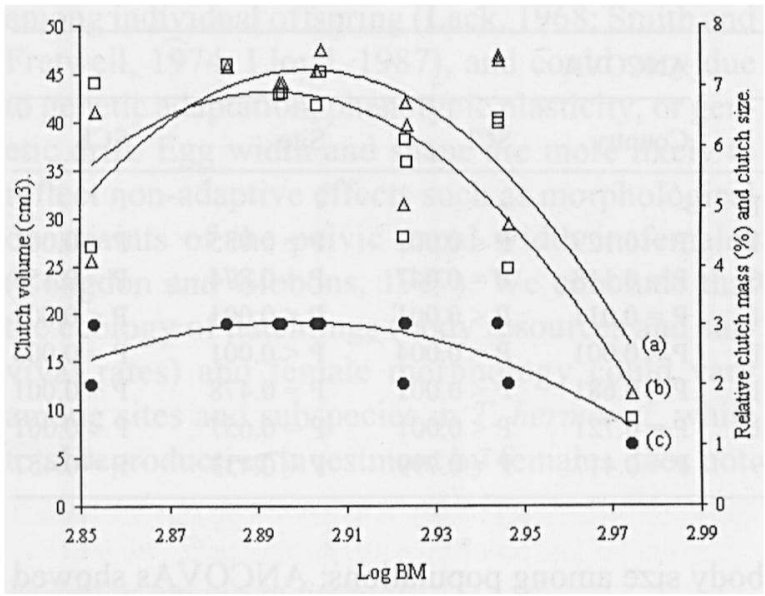

Fig. 2. The variation of reproductive characters of Testudo. $h$. hermanni with body mass (BM). Clutch volume (a, open triangles; $C V=-5384.50 * \log B^{2}+31244 * \log B M-45278.62$; $\left.R^{2}=0.60, \mathrm{p}=0.006\right)$, relative clutch mass $(\mathrm{b}$, open squares; $\mathrm{RCM}=-744.50 * \log \mathrm{BM}^{2}+4307.44 * \log \mathrm{BM}-6223.71 ; R^{2}$ $=0.66, p=0.003)$ and clutch size (c, filled circles; $C S=-299.35$ * $\left.\log \mathrm{BM}^{2}+1734.94 * \log \mathrm{BM}-2510.72 ; R^{2}=0.58, \mathrm{p}=0.008\right)$.

mean size of females with eggs ( \pm S.E.) was $158 \pm$ $1.7 \mathrm{~mm}$, with a mean body mass of $821 \pm 18 \mathrm{~g}$ (range 713-943 g). The proportion of adult females with shelled eggs varied with month, being highest in May (77\%), then April and June (both 50\%); no females with calcified eggs were captured during July. The overall ratio of females with : without shelled eggs was 1.6:1 during the whole reproductive period (between emergence from hibernation and the end of the laying period). This suggests that on average females lay more than one clutch per year, because the interval between clutches is only about 20 days (Collins, 1980; Swingland and Stubbs, 1985), and eggs will only be calcified and visible in X-ray images for part of this time. Clutch sizes ranged from 1-3 (figure 1), with an average of 2.6. Egg length was not related to egg width among females $\left(R^{2}=0.006, P=0.79\right)$. Egg mass and volume were strongly related by the equation $\mathrm{EM}=0.64+1.09 * \mathrm{EV}\left(R^{2}=1, P<0.0001\right)$.

Clutch size, clutch mass and clutch volume were significantly related to egg length, egg mass, egg volume and shape, but not to egg width (table I; equations given by Longepierre, 2001). Egg length, egg mass, and egg volume (but not egg width or shape) were also significantly related to body mass of females according to quadratic curves, but not to the length or condition of females (table I; Longepierre, 2001). The variation of clutch mass, clutch volume, and RCM was largely explained by clutch size, with strong correlations among these clutch characters (table I; Longepierre, 2001). The clutch characters were also significantly related to body mass by quadratic curves (figure 2) but not to the length or condition of females (table I).

\section{Discussion}

\section{Variation among populations}

Females in the Plaine des Maures had calcified eggs from April to June, a similar reproductive season to T. h. hermanni in the Massif des Maures (Cheylan, 1981; Swingland and Stubbs, 1985) and to T. $h$. boettgeri in Greece (Hailey and Loumbourdis, 1988, 1990). Nevertheless some egg, clutch, and female characters did vary among populations of $T$. hermanni in southern Europe (table II). The body size of adult females in the Plaine des Maures was very similar to that previously found in the Massif des Maures. Tortoises from Greece were larger, and ANOVAs showed significant variation of body size both between countries, and among sites in Greece. The larger size of these tortoises from Greece re- 
Table 1. Reproductive characters of female Testudo hermanni hermanni $(n=14)$ with calcified eggs, in the Plaine des Maures, and matrix of $R^{2}$ values between egg, clutch, and female characters (S.E. $=$ standard error; ${ }^{*} P<0.05$, ${ }^{* *} P<0.01,{ }^{* * *} P<0.001$; all other values are not significant $P>0.05$ ).

\begin{tabular}{|c|c|c|c|c|c|c|c|c|}
\hline \multirow{2}{*}{. } & \multirow[b]{2}{*}{ Mean \pm S.E. } & \multirow[b]{2}{*}{ Range $\min -\max$} & \multicolumn{3}{|l|}{ Clutches } & \multicolumn{3}{|c|}{ Females } \\
\hline & & & $\mathrm{CS}$ & $\mathrm{CM}$ & $\mathrm{CV}$ & SCL & $\mathrm{CI}$ & $\log B M$ \\
\hline Egg length (L, mm) & $35.6 \pm 0.5$ & $30.1-38.6$ & $0.67^{* *}$ & $0.62^{* *}$ & $0.62 * *$ & 0.06 & 0.01 & $0.42^{*}$ \\
\hline Egg width (w, mm) & $27.8 \pm 0.2$ & $26.2-29.1$ & 0.10 & 0.24 & 0.25 & 0.05 & 0.02 & 0.03 \\
\hline Egg mass (EM, g) & $16.5 \pm 0.4$ & $13.3-18.0$ & $0.39 *$ & $0.55^{* *}$ & $0.55^{* *}$ & 0.000 & 0.001 & $0.53 *$ \\
\hline Egg volume $\left(\mathrm{EV}, \mathrm{cm}^{3}\right)$ & $14.4 \pm 0.3$ & $11.6-15.8$ & $0.38^{*}$ & $0.53 * *$ & $0.54 * *$ & 0.000 & 0.002 & $0.51^{*}$ \\
\hline Egg shape, L/w & $1.28 \pm 0.02$ & $1.11-1.41$ & $0.43^{*}$ & $0.44^{*}$ & $0.44^{*}$ & 0.11 & 0.03 & 0.12 \\
\hline Clutch size (CS) & $2.64 \pm 0.20$ & $1-3$ & - & $0.95 * * *$ & $0.94 * * *$ & 0.02 & 0.03 & $0.58^{* *}$ \\
\hline Clutch mass $(\mathrm{CM}, \mathrm{g})$ & $44.1 \pm 3.2$ & $13.3-54.1$ & $0.95 * * *$ & - & $1 * * *$ & 0.01 & 0.02 & $0.60 * *$ \\
\hline Clutch volume $\left(\mathrm{CV}, \mathrm{cm}^{3}\right)$ & $38.6 \pm 2.8$ & $11.6-47.5$ & $0.94 * * *$ & $1 * * *$ & - & 0.009 & 0.02 & $0.60^{* *}$ \\
\hline Relative clutch mass (RCM, \%) & $5.77 \pm 0.40$ & $1.44-7.34$ & $0.93 * * *$ & $0.93^{* * *}$ & $0.93^{* * *}$ & 0.08 & 0.01 & $0.66 * *$ \\
\hline
\end{tabular}

Table 2. Comparison of Testudo h. hermanni at two sites in southern France, and with $T$. h. boettgeri in Greece.

Notes: For France, (1) is the Plaine des Maures (this study) and (2) is the Massif des Maures (from Swingland and Stubbs, 1985).

For Greece, (3) is the mean of three sites (from Hailey and Loumbourdis, 1988, 1990) and (4) is the predicted value at $158 \mathrm{~mm}$ SCL.

$P$-values are shown for one-way ANOVAs of country (France versus Greece), and of site in Greece (Alyki, Deskati and Litochoron), and for ANCOVAs of country and of site with SCL as covariates.

\begin{tabular}{|c|c|c|c|c|c|c|c|c|c|c|}
\hline & \multicolumn{2}{|c|}{ France } & \multicolumn{2}{|c|}{ Greece } & \multicolumn{2}{|l|}{ ANOVA } & \multicolumn{4}{|l|}{ ANCOVA } \\
\hline & (1) & (2) & (3) & (4) & Country & Site & Country & SCL & Site & SCL \\
\hline $\mathrm{SCL}(\mathrm{mm})$ & 158 & 161 & 177 & 158 & $\mathrm{P}<0.001$ & $P<0.001$ & - & - & - & - \\
\hline EM (g) & 16.5 & 15.8 & 16.8 & 15.4 & $P=0.654$ & $P=0.001$ & $P=0.129$ & $\mathrm{P}<0.001$ & $P=0.035$ & $P<0.001$ \\
\hline $\mathrm{L}(\mathrm{mm})$ & 35.6 & - & 37.3 & 36.7 & $P=0.013$ & $P=0.286$ & $P=0.118$ & $P=0.047$ & $P=0.874$ & $\mathrm{P}=0.155$ \\
\hline $\mathrm{w}(\mathrm{mm})$ & 27.8 & - & 27.8 & 26.7 & $P=0.905$ & $\mathrm{P}<0.001$ & $P=0.011$ & $P<0.001$ & $P<0.001$ & $\mathrm{P}<0.001$ \\
\hline Shape & 1.28 & - & 1.35 & 1.38 & $P=0.011$ & $P<0.001$ & $P=0.001$ & $P=0.004$ & $P<0.001$ & $P=0.005$ \\
\hline CS (eggs) & 2.64 & 2.89 & 3.77 & 2.75 & $P=0.003$ & $\mathrm{P}<0.001$ & $P=0.681$ & $\mathrm{P}<0.001$ & $P=0.478$ & $\mathrm{P}<0.001$ \\
\hline $\mathrm{CM}(\mathrm{g})$ & 44.1 & 45.8 & 65.7 & 41.4 & $P=0.004$ & $\mathrm{P}<0.001$ & $P=0.721$ & $\mathrm{P}<0.001$ & $P=0.657$ & $P<0.001$ \\
\hline RCM (\%) & 5.77 & - & 6.32 & 6.20 & $P=0.283$ & $P=0.519$ & $P=0.417$ & $P=0.799$ & $P=0.433$ & $P=0.457$ \\
\hline
\end{tabular}

flects the particular populations in which reproduction has been studied (Hailey and Loumbourdis, 1988). Body size varies widely in Greece, and tortoises from the Peloponnese have even smaller body size than French populations (Willemsen and Hailey, 1999). No general body size distinction can thus be made between $T$. h. hermanni and T. h. boettgeri.

The most fundamental reproductive character, relative clutch mass $(\mathrm{RCM})$ did not vary significantly with country, site, or body size, with a mean value close to $6 \%$ in all areas (table II). This value is low compared to squamate reptiles, probably due to restriction of clutch volume and mass by the carapace (Hailey and Loumbourdis, 1988). The clutch characters clutch size and clutch mass did vary significantly with both country and site in ANOVA. This variation was due to differences of body size among populations; ANCOVAs showed no significant effects of country or site after adjusting for the highly significant body size covariate (table II). Mean clutch size and clutch mass were thus higher in Greece than in France, but the values predicted for $T$. h. boettgeri of $158 \mathrm{~mm}$ were similar to those observed in France. Clutch size and clutch mass in the Plaine des Maures were also very similar to those previously reported at the Massif des Maures (table II). We conclude that clutch characters, which are measures of total reproductive investment, show no differences between the subspecies or among sites after body size variation has been taken into account.

Mean egg mass varied significantly with site but not country in both ANOVA and ANCOVA, and with body size covariate. Egg mass in the Massif 
des Maures was similar to that predicted for a Greek tortoise of the same size. Variation in egg mass was therefore local rather than between the subspecies. Egg length varied significantly with country in ANOVA, due to a significant effect of body size; there was no significant effect of country in ANCOVA. There was no significant effect of site on egg length in ANOVA or ANCOVA. Egg width and shape both varied significantly with country, site, and body size in ANCOVA and with site in ANOVA; shape but not width varied significantly with country in ANOVA. Eggs from the Plaine des Maures were wider than predicted for Greek tortoises of equal body size; conversely their values of the shape index (egg length/egg width) were lower. Thus, in contrast to clutch characters, egg characters did vary with country and site after adjusting for differences in body size. Egg mass is a measure of the division of reproductive investment among individual offspring (Lack, 1968; Smith and Fretwell, 1974; Lloyd, 1987), and could vary due to genetic adaptation, phenotypic plasticity, or genetic drift. Egg width and shape are more likely to reflect non-adaptive effects such as morphological constraints of the pelvic canal width in females (Congdon and Gibbons, 1987). We conclude that the ecology of hatchlings (body resources and survival rates) and female morphology could vary among sites and subspecies in T. hermanni, while total reproductive investment by females does not.

\section{Variation among individuals}

Egg length, egg mass, egg volume, and shape were significantly related to clutch size, clutch mass, clutch volume, and female mass, but egg width showed no significant relationships (table II). These within-population relationships were opposite to among-population comparisons, where egg width showed significant variation with country, site, and body size while egg length did not (table II). This contrast can be explained by noting that egg width may be constrained by the pelvic canal width, while egg length is not. Egg width was thus much less variable in the Plaine des Maures (range 26.2-29.1 $\mathrm{mm}$ ) than egg length (range $30.1-38.6 \mathrm{~mm}$ ), and so more likely to show significant differences to other populations. Egg length showed more individual variation, and was thus less likely to differ significantly among populations.

Egg and clutch characters were not related to the length or condition of females, but they were related to their body mass according to quadratic relationships (figure 2). The lack of effect of condition is expected if the carapace limits the total volume of the body (Hailey and Loumbourdis, 1988), so that increase in eggs reduces the volume of the gut rather than increasing total mass (Hailey and Loumbourdis, 1990). The lack of effect of body length is counter to the pattern found among populations (table II) where larger females had more eggs and higher clutch mass. Clutch size usually increases with body length within populations, although fecundity may decrease again in the largest individuals (Hailey and Loumbourdis, 1988, 1990), perhaps because of old age. The curved relationships" of reproduction to body mass found here could also be due to reproductive senility, suggesting that this is a general phenomenon in populations of longlived T. hermanni. Some decrease of reproduction with age was indeed necessary in the model of optimum adult female size, which otherwise predicted body sizes much larger than observed (Willemsen and Hailey, 2001).

\section{Conclusion}

Reproductive characters of Testudo hermanni vary among populations after correcting for differences in body size. Differences among sites were as large as those between France and Greece, showing that local variation is as large as any subspecific differences. Such local variation should discourage relocation of the threatened $T . h$. hermanni, even between populations within the same region. This suggests that tortoises should be conserved in situ, rather than relocated as has been practised in France (Devaux 1990). More than 6000 tortoises were released from 1986-1995 in the Plaine des Maures, the Levant islands, the Esterel region and other (unpublished) areas, without considering the possibility of local variation. Fortunately these individuals were permanently marked and those recovered were excluded from this study. There was 
insufficient time for any offspring of those released in the study area to have become mature; any reproduction of relocated individuals will complicate future studies, which will thus need to include genetic analysis.

\section{Acknowledgements}

We thank the collective of the Cannet des Maures and society "Meilland" for their help during this work, and two referees for helpful comments. This study was supported by the grant DGAD/ SRAE No. 96103 form the ministerre de l'Amenagement du Territoire et de l'Environnement.

\section{References}

Aubert G, Loisel R. 1971. Etude des groupements des IsoetoNanojuncetea et des Helianthemetea annua dans le sud-est Méditerranéen Français. Ann. Fac. Sci. Mars. 45: 203-241.

Barbero M. 1965. Groupements hygrophiles de l'Isoetion dans les Maures. Bull. Soc. Bot. Fr. 112: 276-290.

Bour R. 1986. L'identité des tortues terrestres européennes: Spécimens-types et localités-types. Rev. Fr. Aquar. 13: 111122.

Cheylan M. 1981. Biologie et Ecologie de la tortue d'Hermann Testudo hermanni Gmelin, 1789. Contribution de l'espèce à la connaissance des climats quaternaires de la France. Ecole Pratique des hauts Etudes, Montpellier, France.

Coleman G. 1991. Measuring parental investment in non-spherical eggs. Copeia. 1092-1098.

Collins P.W.P. 1980. The captive breeding of Mediterranean tortoises in Britain. In: The care and breeding of captive reptiles. Townson S, Millichamp NJ, Lucas DGD \& Millwood, AJ (Eds), Brit. Herp. Soc., London, U.K., 21-36.

Congdon JD, Gibbons JW. 1987. Morphological constraint on egg size: a challenge to optimal egg size theory. Proc. Nat. Acad. Sci., USA. 84: 4145-4147.

Cruce M, Raducan I. 1976. Reproducerea la broasca testoasa de uscat (Testudo hermanni hermanni Gmelin). Stud. Cer. Bio. Buc. Ser. Biol. Anim. 20: 175-180.

Devaux B. 1990. Réintroduction de tortoues d'Hermann (Testudo hermanni hermanni) dans le massif des Maures. Rev. Ecol. Terre Vie. 5: 291-297.

Diemer JE, Moore CT. 1994. Reproduction of gopher tortoises in north-central Florida. Fish and Wildl. Res. 13: 129. 137.

Hailey A, Loumbourdis NS. 1988. Egg size and shape, clutch dynamics and reproductive effort in European tortoises. Can. J. Zool. 66: 1527-1536.
Hailey A, Loumbourdis NS. 1990. Population ecology and conservation of tortoises: demographic aspects of reproduction in Testudo hermanni. Herpetol. J. 1: 425-434.

Hellgren EC, Kazmaier RT, Ruthven DC, Synatzske DR. 2000. Variation in tortoise life history: demography of Gopherus berlandieri. Ecology. 81: 1297-1310.

Lack D. 1968. Ecological Adaptations for Breeding in Birds. (ed. Chapman and Hall), London, U.K.

Lavagne A, Marino ML, Rebuffel G. 1998. Commune de Vidauban, site $\mathrm{N}^{\circ} 6$ Commune du Cannet des Maures la Pardiguière nord. (ed. S.I.V.O.M. du Centre Var), Le Luc en Provence, France.

Lloyd DG. 1987. Selection of offspring size at independence and other size-versus-number strategies. Am. Nat. 129: 800817.

Loisel R. 1971. Les cistaies calcifuges de Provence. Ann. Fac. Sci. Mars. 46: 63-81.

Longepierre S, 2001. Ecophysiologie de Testudo hermanni hermanni Gmelin, 1789 : Evaluation des contraintes environnementales et alimentaires en milieu naturel dans le Sud de la France. Thesis, Ecole Normale Supérieure de Paris UCBL I. (Ed. ANRT, Grenoble). France.

Longepierre S, Hailey A, Grenot C. 2001. Home range area in the tortoise Testudo hermanni in relation to habitat complexity: implications for conservation of biodiversity. Biodivers. Conserv. 10: 1131-1140.

Smith CC, Fretwell SD. 1974. The optimal balance between the size and number of offspring. Am. Nat. 108: 499-506.

Sokal RR, Rohlf FJ. 1994. Statistical Tables. $3^{\text {rd }}$ edn. Freeman and Company, New York, U.S.A.

Stubbs D, Hailey A, Pulford E, Tyler W. 1984. Population ecology of European tortoises: review of field techniques. Amphibia-Reptilia. 5: 57-68.

Swingland IR, Stubbs D. 1985. The ecology of a Mediterranean tortoise (Testudo hermanni): reproduction. JZool. Lond. 205: 595-610.

Wallis IR, Henen BT, Nagy KA. 1999. Egg size and annual and annual egg production by female desert tortoise ( $\mathrm{Go}$ pherus agassizii): the importance of food abundance, body size and date of egg shelling. J. Herpetol. 33: 394-408.

Willemsen RE, Hailey A. 1989. Status and conservation ot tortoises in Greece. Herpetol. J. 1: 315-330.

Willemsen RE, Hailey A. 1999. Variation of adult body size of the tortoise Testudo hermanni in Greece: proximate and ultimate causes. J. Zool. Lond. 248: 379-396.

Willemsen RE, Hailey A. 2001. Variation in adult survival rate of the tortoise Testudo hermanni in Greece: implications for evolution of body size. J. Zool. Lond. 255: 43-53.

Zar JH. 1984. Biostatistical Analysis, $2^{\text {nd }}$ edn. Prentice-Hall International, Englewood Cliffs, New Jersey, U.S.A.

Received: 15 November 2002 